\title{
Traces of a mobile field: ten years of mobilities research
}

\author{
James Faulconbridge, Lancaster University (j.faulconbridge@lancaster.ac.uk); \\ Allison Hui, Lancaster University (‥hui@lancaster.ac.uk)
}

Please cite as: Faulconbridge, JR. Hui, A. (2017) Traces of a mobile field. Ten years of mobilities research. In Faulconbridge, J. Hui, A (2017) (Eds) Traces of a mobile field. Ten years of mobilities research. Routledge, London \& New York, 1-14. ISBN 978-1-138-70858-7

\begin{abstract}
Since the launch of this journal ten years ago, the field of mobilities research has developed at a rapid pace. In this editorial introduction we explore how this development has been curated, how the field has evolved, and what maturation might mean for mobilities research. After reviewing how early editorials encouraged particular trajectories of development within mobilities research, we introduce the paper in this special issue, which build upon and re-shape key discussions that have emerged in the last decade. Drawing out issues of power, interdisciplinarity, social processes and futures, the papers raise important questions about not only how understandings of mobilities are changing, but also how the field of mobilities research is itself on the move. Taking up these themes, we examine how understanding mobilities research as a field, following Bourdieu (1984), contributes to considerations of the potential for future struggles, fragmentation, and subdisciplines. We argue that the open nature and strategic diversity of the mobilities field has fed the successes of the past decade, and therefore needs to remain a priority in the future - with a careful balance curated between convergence around key themes and the exploration of varied 'internal goods' (MacIntyre 1985) which remain an important source of inspiration and creative potential within the field.
\end{abstract}

Keywords: mobilities, fields, futures, internal goods, interdisciplinary, power, academic practices 


\section{Introduction}

In September 2013, the paths of many colleagues and friends coalesced at the 'Global Mobility Futures' conference at Lancaster University, UK, to celebrate the tenth anniversary of the Centre for Mobilities Research (CeMoRe). This gathering sparked many exciting conversations about mobilities research, a field that some of the participants first explored during CeMoRe's 2004 conference on 'Alternative Mobility Futures'. More importantly, however, it affirmed that interactions within mobilities research remain vibrant, creative, and generative. In this special issue, which emerged from the 2013 conference and also marks ten years since the launch of this journal in 2006, we seek to capture the creative momentum of mobilities research and critically reflect upon how the field emerged and what its future might hold.

As a journal, Mobilities was born at a crucial moment. Many interdisciplinary discussions about the topic of mobility were emerging, in eclectic and dispersed contexts. By bringing together ongoing conversations, and providing a forum for further dialogue, the journal helped to encourage a convergence of interests around the dynamics, stakes, and empirical study of mobilities. Alongside the first issue of the journal, the year 2006 also saw the publication of a special issue in Environment and Planning A. The editorials for the two issues (Hannam et al., 2006; Sheller and Urry, 2006) have since become the starting point for most discussions of the 'mobilities turn'. From this point on, the last decade has seen a proliferation of mobilities scholarship, as testified by the success of this journal (which has expanded from three to five issues per year) and the many published handbooks (Adey et al., 2014b), special issues (Anim-Addo et al., 2014; Bajc et al., 2007; Barker et al., 2009; Basu and Coleman, 2008; Conradson and McKay, 2007; Fortier and Lewis, 2006; Gill et al., 2011; Richardson, 2013) and reviews of the field (Cresswell, 2011, 2012, 2014; Merriman, 2015).

It could be tempting on an anniversary such as this to summarise and to ask what is new about the scholarship published under the badge of mobilities research. Inevitably, though, answering such a question is an impossible task. Not only do assessments of novelty vary in relation to how they are situated and contextualized, presenting particular problems for interdisciplinary fields, but such assessments would also be slippery and fleeting given the heterogeneity and continual development of the field.

Indeed, the diversity of the papers in this special issue is a testament to both the dynamic development of mobilities research and its broad scope. After ten years, the vibrant and interdisciplinary set of dialogues that characterize the field has largely rendered moot the question of whether there really was a mobilities turn or paradigm shift. More interesting, therefore, are questions of how links and connections, histories and futures, become intertwined in 'state of the art' mobilities research. The papers in this special issue are all exemplars of how the past decade of research has opened up new insights into the place of mobilities in societies. They also highlight how attempts to look forward towards new conversations, understandings, and interventions in a mobile world will be embedded in, and emerge from, the more or less deliberate transformations invoked by the rise of the mobilities field. They remind us, then, that the state of the art has its own history, politics, and trajectory. 
Therefore, in this editorial, rather than attempting to summarize the diverse empirical, theoretical, and methodological themes of this special issue, we step back to critically reflect upon mobilities as a field of study with its own past and future. This stems from the conviction that the vitality of mobilities research is tied to not only the processes it studies, but also the practices of mobilities researchers. Ensuring the vitality and creativity of mobilities research in the next decade is, therefore, not only about reflecting upon the understandings and politics of the mobilities we study, but also about situating our own interactions within the understandings and politics of research fields.

Our reflections begin by considering how, in 2006, the future of the nascent field of mobilities research was shaped by editorial calls to join an interdisciplinary and empirically-driven project. We argue that these initial framings of mobilities research were central in shaping what was to become a strategically diverse field. After introducing how the special issue papers represent traces of the field which gather and redirect existing conversations, the second half of the paper considers more closely what it means to address mobilities research as a 'field' (Bourdieu, 1984). Engaging with discussions of the emergence and maturation of organizational fields, as well as the struggles and rewards of competition within fields, it highlights how treating mobilities research as a field has implications for imagining the next decade of development.

\section{Curating new trajectories}

Our initial point of departure is to reflect upon the genealogy of mobilities research and how particular trajectories within it have enabled creativity and contributions in the last decade. While authors in Adey et al.'s (2014b) recent handbook consider the genealogies of several (sub)disciplines contributing to work on mobilities, we turn instead to the two 2006 editorials and how they both recognized and encouraged particular lines of exploration. These initial interventions, we suggest, have significantly energized subsequent work and contributed to the formation of a distinct, interdisciplinary field of mobilities research.

Though the editorials by Hannam et al. (2006) and Sheller and Urry (2006) are regularly cited in reference to a 'mobilities turn' or 'mobilities paradigm', it is important to recognize that their contribution was largely one of curation and categorization. The imperative of both was to make a discursive injunction by trying to name and re-categorize work in order to develop a mobilities agenda. The authors were thus careful to position the mobilities turn as something that in many ways had already happened. Subsequent tensions and discussions have arisen around this labelling how for instance it relates to the historicization of mobilities scholarship (Cresswell, 2010) and the existence of coherent paradigms within the social sciences. This can be seen as evidence of how this knowingly 'provocative labelling' (Adey et al., 2014a, p. 2) provided momentum for new discursive engagements and a re-thinking of previous segmentations and separations within social scientific literature. There is, nonetheless, still an outstanding question: what made the discursive, if not paradigmatic, shift signalled by the two editorials compelling, given that there were already decades of mobilities studies within other disciplines such as anthropology, geography, migration and transport studies? 
In our reading, the editorials' key contribution was to propose a transformation and re-arrangement of research practices in order to foreground mobility, rather than seeing it as a constituent of larger social processes. This implies the need to investigate empirical cases involving mobilities without initially presuming that they can be explained through existing theoretical or disciplinary framings. In this sense, mobilities are not 'superfluous' or 'exceptional', but worthy of extended attention (Adey et al., 2014a, p. 3). Mobilities research involves a 'style of analysis' in which mobilities are treated critically and in context (Adey et al., 2014a, p. 2). In some ways this move can be read as a simple validation of mobilities as objects of study. But it also created a space for considering what was, at the time, not orthodox in some disciplines such as sociology (Sheller, 2014; Urry, 2000). Encouraging efforts to put mobilities centre stage thus implicitly challenged various (sub)disciplinary assumptions of what was relevant and irrelevant, consequential and inconsequential, central and peripheral within the social world. The invitation to consider mobilities provided, then as now, a space to question 'normal' assumptions and categories, challenge segmentations and boundaries within communities of knowledge, and explore creative and experimental approaches to studying the social world.

This call to examine mobilities on its own terms suggests, but is not premised upon, particular theoretical and methodological approaches. Indeed, notable has been the resultant theoretical and methodological experimentation associated with the study of diverse empirical topics (as the papers in this special issue illustrate). While, for instance, Urry has outlined a set of theoretical concepts that support considerations of mobilities (2007: chapter 3), these do not represent an orthodoxy or construct a new grand narrative. Rather, looking back over the past decade of research, it is possible to identify streams of scholarship that develop different theories, methods, and 'styles' of analysis in order to understand mobilities. This is reflective of the encouragement given in the two editorials to study diverse empirical cases and retain a sense of openness about the theoretical and methodological resources that might be appropriate. Hence, 'The new mobilities paradigm suggests a set of questions, theories, and methodologies rather than a totalising or reductive description of the contemporary world' (Sheller and Urry, 2006, p. 210). This suggests, and research published in the last decade appears to confirm, a primary aim of creating a space where studies of diverse mobilities might be investigated without the constraints imposed by pre-existing disciplinary frameworks.

Though contemporary theoretical and methodological approaches remain as heterogeneous as those in the initial lists suggested by Sheller and Urry (2006), several important trajectories can nonetheless be identified. Theoretically, for instance, we note the rise of an ontological position that is more process-, performance- and practice-oriented, with mobilities being seen as emergent and in need of theorisation as such. This involves, for instance, the use and development of work by Goffman (Jensen, 2006, 2010; Licoppe, 2009; Yeoh and Huang, 2010) and de Certeau (Bissell, 2009; Farías, 2010; Kidder, 2009), as well as on affect (Bissell, 2010; Conradson and Latham, 2007; Jensen et al., 2014), practices (Aldred and Jungnickel, 2013; Benson, 2011; Cresswell and Merriman, 2011; Hui, 2013; Larsen, 2008b), creating networks (Blok, 2010; Hui, 2012; Larsen et al., 2006; Larsen, 2008a; Nowicka, 2007; Ren, 2011) and the non-representational (McHugh, 2009; Spinney, 2011; Vannini, 2011). Relatedly, empirical analyses have privileged not the functionality of moving from $A$ to B but experiences and socio-cultural constructions of mobilities (Cresswell, 2006; Jensen, 2009). The methodological challenges and opportunities of studying mobilities have also contributed to the emergence of 'mobile methods' that combine and re-orientate traditions such as ethnography with 
the use of new technologies such as the smart phone (Büscher and Urry, 2009; Büscher et al., 2011; Fincham et al., 2010; Hein et al., 2008). All of these developments stem from prioritising the specificities of mobility itself, and mark a contrast with studies in which mobility is treated as an incidental part of a wider phenomenon.

The development of particular theoretical and methodological approaches is also matched with a number of distinctive characterisations of the phenomena that fit under the mobilities umbrella. These are even more diverse than the theoretical and methodological developments outlined above. This was perhaps inevitable since the editorials a decade ago explicitly promoted interdisciplinary investigations of mobilities (Hannam et al., 2006, pp. 2, 16). An interest in creating dialogue across existing disciplinary boundaries not only suggested but required conceptual openness: 'Mobilities in this paradigm is thus used in a broad-ranging generic sense' (Sheller and Urry, 2006, p. 212). Hence, different types of movement (of people, objects, capital, information), as well as their intersections and dynamics across multiple systems and scales, have been of concern (Hannam et al., 2006, p. 1). An attention to connections and flows, exclusions and obstacles, has highlighted how heterogeneous mobilities reproduce systems of governance and politics, as well as situated experiences and engagement. All of this creates space to move beyond some of the more traditional foci for research, such as embodied travelling by car, train or any other means. Mobilities research has taken such cases seriously, but emphasized the importance of connecting them to broader processes and problems.

Since the 2006 editorials, mobilities research has thus emerged around both shared interests and important departures. These have contributed to many exciting trajectories of development that are addressed, in part, by the papers in this special issue.

\section{Traces of a mobile field: the special issue papers}

The above description is, of course, no more than a snapshot of developments over the past decade. Likewise, the papers in this special issue gather a diverse set of traces of the ever-shifting field of mobilities research. They are, for one, traces of the anniversary conference and its heterogeneous conversations. But they also trace major areas to which mobilities research has contributed in the past decade, and to which it may contribute in the future. In this way, they represent an (inevitably) incomplete picture of advances and accomplishments that have emerged over the past decade, continually re-making understandings of 'state-of-the-art' mobilities research. Uniting all of these papers, as would be expected, is the style of interdisciplinary scholarship that has come to define the field in the past decade; analyses de-familiarising apparently familiar topics and allowing mobility in and of itself to emerge centre stage. Hence each paper forges links to varied histories of mobilities research, extending some trajectories and redirecting others. Histories are linked to patterns of inequalities, discourses of emergence and development, and varied interdisciplinary encounters. The papers also connect and move between mobile units, terrains of negotiation and contestation, and groups of differentially mobile subjects. In this way, they sit at the intersections of many stilldeveloping trajectories of mobilities research.

The first two papers (Sheller, this issue; Adey, this issue) reflect upon evolving research agendas, asking to what conversations and problems mobilities research might better contribute. In 
particular, inequalities, highlighted by Kaufmann et al. (2004) as a constituent feature of mobility, and emergencies are highlighted as areas in need of further theoretical development and attention. Sheller therefore engages with the work of Foucault, and Adey broader themes around governance, in order to build up theoretical resources for addressing how the unevenness and politics of mobilities are manifest in a range of sites and cases. Their discussions highlight how the lack of a grand theory within mobilities research need not lead to the ignorance of systemic processes and problems - rather, mobilities scholars build up appropriate interdisciplinary vocabularies and understandings to fit the complex and changing sites they study. These contributions thus suggest the potential for new agendas and theoretical development in the next decade of research.

Subsequent papers by Lin and Hui (both this issue) consider how mobilities research might be further developed through engagement with cases that are exceptional within existing discussions. A range of studies on aeromobility over the past decade (Adey, 2008; Budd, 2011; Burrell, 2008; Cwerner et al., 2009; Lassen, 2006) inform the work of Lin (this issue), who highlights the Western biases of many existing studies and the corresponding failure to understand how significant aeromobile assemblages are for non-Western economies and societies. Similarly, Hui (this issue) reflects upon interdisciplinary dialogues between migration and mobilities scholars, unpicking key points of friction and making the 'migrant exceptionalism' perpetuated by both groups both a target of critique and an inspiration for future interdisciplinary engagement. In different ways, these papers show that reflection upon how mobilities research is conducted might open up new empirical sites, new interdisciplinary interactions, and new understandings of mobilities themselves.

Papers by Merriman and Licoppe (both this issue) then examine relationships between complex transformations and mobile things in urban environments. Though Sheller and Urry noted a dearth of research on automobility in their editorial (2006), this has been redressed by mobilities scholars in the last ten years (Böhm et al., 2006; Conley and McLaren, 2009; Featherstone et al., 2005). Such discussions are here extended by Merriman (this issue), who highlights how urban environments have been transformed by not only cars, but by the processes of infrastructuring that surround materialities and imaginations of car parking. Laurier (this issue) then considers a different aspect of urban transformation, reviewing how mobile locative media have transformed mobile subjects and encounters through the creation of 'pseudonymous strangers' and the negotiation of the seams and overlaps between virtual and physical spaces.

The embodied experience of mobile subjects has been another important area to which mobilities research has contributed in the last decade. Laurier et al.'s paper (this issue) takes up the intersection between mobile subjects and mobile methods, looking at how embodied, interpersonal performances of walking become reconfigured through the use of mobile devices and map apps. Drawing upon detailed conversation analysis of video and screen-captured data, their paper highlights how the exploration of new technologies in mobile methods have made it possible to attend closely to the meanings and movements of mobile bodies.

The final two papers by Johnson and Martin (this issue) and Reese (this issue) draw attention to the centrality of questions about futures in mobilities research. For Johnson and Martin (this issue) this relates to new technologies of mobility, in the form of space travel, and how actors within this emerging sector draw upon discourses of tourism and other modes of transportation to envision future mobilities. In contrast, Reese (this issue) looks at an 'old' technology - the automobile - 
asking how the stories we tell about automobility have implications for the future, and in particular for reducing carbon emissions as an urgent public policy priority. These final papers remind us, then, both of the importance of discourses and imaginations of mobilities past, present and future, and of the intricate relationships between the field of mobilities research and the ever changing societies that we study.

While these special issue papers highlight, in different ways, the trajectories of mobilities research introduced in the previous section, they also raise questions about what happens next and where mobilities research goes from here:

- How might mobilities research remain exciting and compelling, while taking seriously the power dynamics that mark both research practices and the cases they study?

- To what extent has mobilities research not only challenged some assumptions and boundaries, but also started to reproduce others?

- To what extent is coalescence around a number of theories and associated debates needed? What benefits or risks could this entail?

- How do the stories we tell about mobilities research suggest what is permanent or changeable about the practices it reproduces or studies in the future?

These questions are important because of what is at stake in the study of uneven mobilities and unsustainable mobilities. They are also important because, as the last decade has shown, how studies of mobilities are framed and approached have implications for the diversity of subsequent contributions. The following sections therefore draw upon understandings of 'fields' (Bourdieu, 1984) to engage with these questions, reflect critically upon last decade of mobilities research and imagine what the next decade might bring.

\section{The politics of emerging research fields}

The openness of 'mobilities' as a concept has undoubtedly enabled exciting and fruitful discussions that challenge 'normal' categories and units of disciplinary study. It has also demanded new considerations of complexities and the dense webs of social and material relationships that underlie life on the move. But, the result of this is that while mobilities research is drawn together by broadly shared concerns and curiosities, after a decade of development it is also marked by significant internal variations. Widespread agreement about basic terms or approaches is not only implausible, but also inappropriate given the emphasis on flexible sets of theoretical and methodological resources. How then might we assess and reflect upon the form this development has taken?

One way of thinking about the development of research over the past decade is to ask whether we can see the emergence of a research field as a result of the efforts of contributors to the mobilities project. By using the term field we allude to ideas associated with the work of Pierre Bourdieu (1984), as well as a range of other literatures including those on institutional fields (DiMaggio and Powell, 1983; Scott, 1994). We use the question of the emergence of a field of mobilities research as a way into thinking about two issues. First, we ask the most fundamental question: to what extent might the mobilities project of the past decade be conceptualised as a process of field emergence? In doing this we consider both the process and politics of emergence and in turn what is at stake in 
such a project. Second, we consider the potential struggles of the next decade, and draw attention to the important role sub-fields could play in shaping future interactions and struggles.

Firstly, then, we consider what field emergence might involve. A field is an arena with 'a common meaning system' (Scott, 1994) p207-208). As such, a field is a recognised area of social life, with rules, norms and cultures that shape the actions of field members. The strength of a field's meaning system will, however, vary over the course of its emergence. Fligstein and McAdam (2012: 86-87) suggest that emerging fields are occupied by groups that orientate to one another because of shared interests, but which are yet to fully agree on the 'rules of the game'. This explains the relatively weak struggles over what mobilities research is and is not; in the first decade the 'rules of the game' were in the process of emerging and, as such, no individual or group was able to define what was inside and outside of the field of research. Indeed, studies of attempts to create new fields (Hargadon and Douglas, 2001; Navis and Glynn, 2010) have shown that the main efforts involve distinguishing the new field from those already existing, whilst also explaining the nature of the work of a new field in a language comprehendible to important audiences. This accounts for the simultaneous efforts both to carve out mobilities as a distinctive research arena that focuses on understudied phenomenon, whilst also highlighting the contributions of the field in relation to wider social scientific debates. Justifying and emphasizing the importance of mobilities research as a field has, then, perhaps been the key struggle of the first decade as a part of efforts to ensure recognition and comprehension within the social sciences.

The primacy of this struggle helps to explain why it is less clear whether mobilities research fulfils Scott's second criterion for the existence of a field. In addition to having 'a common meaning system', Scott suggests that a field's 'participants interact more frequently and fatefully with one another than with actors outside of the field' (Scott, 1994, pp. 207-208). Due in part to the interdisciplinary nature of mobilities research, this intensity of interaction would be both difficult to assess, and potentially inappropriate to expect. Interdisciplinary exchange, after all, benefits from the incomplete overlapping of multiple academic communities, whose differences and debates inform new insights. The increasing acceptance of interdisciplinary work also means that it is now more common for researchers to be intermittently engaged within a range of different fields - some out of interest, and others out of obligation (as for instance in the case of research assessment exercises in the UK or departmental re-organizations where new fields are dictated by others). One might thus challenge the appropriateness of Scott's criterion within an interdisciplinary context, and in a context in which careers are connected to university structures still often centred upon metadisciplines (economics, geography, sociology etc.) and their fields. That is, when establishing a new field, interactions with actors outside it are incredibly fateful, and have significant consequences for recruiting new participants and establishing the field's importance. Hence, as Fligstein and McAdam (2012) propose, we need to be sensitive to the relationships and interactions that span between fields given the networked nature of contemporary social life.

Nonetheless, even if the potential limits of Scott's definition are accepted, there are suggestions that increasingly interactions between mobilities researchers, including through papers, projects and this journal, are becoming important to agenda setting, theory development, and careers within a distinctive area (i.e. field) of academic life. Repeated discursive articulations of the 'mobilities paradigm' or 'mobilities turn' within publications, conferences, and meetings help to further build up a set of shared understandings of social life and approaches to research. It seems, then, that a field 
of mobilities research is repeatedly discussed (Adey et al., 2014b; Cresswell, 2011, 2012, 2014; Merriman, 2015) and is emerging as a fateful 'space' for its participants. What then are the implications of such a trajectory of development for the next ten years?

\section{Maturation and new challenges}

The literature on fields points to how, after emergence and as maturation occurs, new considerations are likely to come into play. Fligstein and McAdam (2012, p. 88) show that in the maturation period roles are carved out for different actors and more sustained attempts are made to create a framework that allows those inside the field to understand the 'rules of the game'. As a part of this coalescence, power relations begin to develop. Those in 'incumbent' positions who play a powerful role in defining the field sit alongside 'challengers' who may have different views of what the 'rules of the game' should be, but perhaps not the resource or motivation to question the emergent consensus. Hence, moving into the second decade of an explicitly acknowledged mobilities turn, one would expect struggles between participants and non-participants of the field (i.e., over what mobilities research is and why it is distinctive) to fade in importance relative to the struggles and competition between mobilities researchers. This could, for example, lead to the emergence of some 'central features' (Urry, 2007, p. 46) and 'lineaments' (Urry, 2007, p. 59) of the field. In any case, the potential for struggle raises important questions about the nature of competition and power within fields, which seem very relevant for the next decade.

Bourdieu's (1984) discussion of fields, and in particular his use of games as a metaphor for the struggles and competition that go on within them, provides a useful starting point for examining such questions. For Bourdieu, interactions within fields are oriented towards increasing one's relative power and prestige compared to other members. Fields thus involve competitions for what MacIntyre calls 'external goods' such as power, prestige or money, which once obtained 'are always some individual's property and possession' $(1985$, p. 190). The competition for these goods, what Bourdieu would understand in terms of capitals, is oriented towards individual gains, but based upon a shared understanding of, and commitment to, the values and stakes they reinforce.

Yet, as Maclntyre highlights, external goods are not the only ones to which power and politics can be oriented. In the course of striving for shared standards and purposes, people also realize 'internal goods' that are 'the outcome of competition to excel, but ... [whose] achievement is a good for the whole community who participate in the practice' (Maclntyre, 1985, pp. 190-191). Competition thus also begets collective gains, such as increases to shared knowledge or the development of shared methods. Whereas the accrual of external goods can be easily understood and compared across different fields, only experts within a practice can judge the accrual of internal goods, as they understand the practice's unique values and rewards (Maclntyre, 1985, pp. 188-189).

How do external and internal goods operate within mobilities research? On one hand, contributing to mobilities research and its establishment as a field has undoubtedly involved the accumulation of external goods for the academics involved - citations, speaking engagements, prestige and promotion. Yet the dynamics of these goods will change as the field matures, since it can be easier to gain prestige from establishing a new field than from excelling within an existing one. One would expect these goods to become more varied and competitive within the mobilities community, in 
such a way that positioning within it and not only within broader social scientific fields is clearly at stake. On the other hand, however, there are internal goods that arise from interactions within the mobilities community - encountering new ideas, having a diverse interdisciplinary forum to explore, engaging with new networks of people. These internal goods are not entirely separable from the external ones, which inevitably relate to internal excellence (Knight, 1998, p. 113), but serve to make competition and community interaction inherently rewarding.

The comparative privileging of internal and external goods is important to reflect upon. As Knight highlights, Maclntyre's discussion of goods takes on important political implications when he connects it to the institutions that organize and help sustain practices: 'these indispensable institutions constantly threaten to corrupt practices and demoralize practitioners, to subordinate pursuit of internal goods to that of external goods' (Knight, 1998, p. 11). For Maclntyre, this is extremely problematic. His emphasis upon internal goods of excellence is thus part of a broader move to foreground them within practices, institutions and politics. Focusing too closely upon fields and their struggles for external goods can be politically problematic because it suggests that the rewards of competition 'naturally' accrue to individuals, and positioning is thus an individual responsibility and struggle. In this context, Warde's (2004, p. 25) suggestion that discussions of fields be supplemented by considerations of practices, which are 'cooperative, pluralistic and orientated towards internal goods,' is helpful. It provides space to discuss the relationship between internal and external goods, as well as political struggles over the extent to which practices contribute to individual or collective gains.

This discussion suggests the importance of ongoing academic practices in shaping what the next decade of mobilities research will become. We argue that how field interactions are structured will be crucial to the flourishing of mobilities research in the future, particularly as themes and methods of mobilities research become even more established and perhaps less strongly linked to external goods. Critical reflection on and interventions into the structures and practices of the field could ensure that in the next decade it is not only a space to examine topics, theories, and methods not legitimated by other disciplines, but that it is also a space in which to cultivate internal goods unique from those in other interdisciplinary fields. In this way, using understandings of fields to reflect upon dynamics within mobilities encourages consideration of not only what mobilities research studies, but how mobilities researchers are engaged in building up shared resources and encouraging collective gains.

One example of how further space for cooperative and creative internal rewards might be fostered relates to the development of sub-fields. One of Fligstein and McAdam's (2012) key arguments is that the nesting of fields is a fundamental feature of social life, and Abbott has made a similar point about the fractal nature of disciplines (2001). For our purposes here, we can translate such ideas into thinking about how the mobilities field is already nested within the wider social sciences, but will likely itself splinter into multiple nested sub-fields. What does this imply? A sub-field will, to some extent, share 'rules of the game' with the wider field. So, for instance, we might expect the emphasis on studying mobilities in and of themselves to be shared across sub-fields. But sub-fields will also be differentiated in terms of agendas, power structures and rules. One can imagine how sub-fields could emerge around work that focuses on particular theorists, as a recent special issue on Foucault (Manderscheid et al., 2014) and papers in this issue (Adey, Sheller) also imply. Since such sub-fields have yet to fully emerge and there is a wide range of possible foci-empirical, theoretical, 
methodological - this remains an important moment in which to consider the implications of different configurations.

For example, the formation of sub-fields around theoretical traditions could emphasise or reproduce theoretical debates already well-rehearsed in other disciplines. Alternately, the formation of subfields around empirical topics such as migration or tourism could discourage creative engagement across the boundaries of these themes, which Hui and Johnson and Martin (this issue) have highlighted. One provocation premised on the value of openness would be to pursue less traditional connections - with sub-fields emerging for instance around the 'qualities', 'materialities' or 'events' that Adey et al. draw attention to (2014a). Another would be to form sub-fields around broad problems such as the politics and ethics of diverse mobilities (Cresswell, 2010), theorising mobilities outside the West (Lin, this issue; Sheller, this issue; Adey, this issue), situating embodied mobilities (Laurier et al., this issue, Licoppe, this issue), and systems of heterogeneous mobilities (Reese, this issue; Merriman, this issue). Since overly rigid or isolated sub-fields seem to us likely to stifle the flexibility and creativity that has made mobilities an appealing interdisciplinary field, there is reason to actively cultivate practices and sub-fields that embed collegiality, open-mindedness, and the destabilization of hierarchies between early career and senior academics as fundamental values.

More fundamentally, this relates to the tricky challenge of managing the fine line between coherence and closure. Resisting the urge to have a specific line on what mobilities research is and is not (closure) would seem important if we are to build upon the successes of the past decade.

Resisting the entrenchment of a 'canon' or other markers of internal prestige and hierarchy (closure) would also seem important for maintaining the openness and collegiality of the past decade. As the discussion above makes clear, mobilities research is not united by a coherent ontological position (as with for example actor-network theory), or by an established methodological approach (as with anthropology's foregrounding of ethnography), and the creation of a 'canon' could move towards closing down these areas of diverse discussion. Yet ensuring that a number of core agendas emerge so that diversity does not become overwhelming, or prevent further dialogue and even creative syntheses, also matters. Refinement and specialization can be important for sparking further enrichment and collective rewards. The reflexivity with which we approach questions of coherence or closure, openness or consensus will shape future trajectories, questions and perhaps the 'rules of the game' that unite sub-fields, as they emerge. We therefore argue that in the next decade mobilities researchers will need to attend not only to questions of how mobile worlds can be studied - in which contexts and using which theories and methods - but also to questions of how the field itself is represented, envisioned, and ever on the move.

\section{Conclusions}

By highlighting questions about the emergence of mobilities as a research field, we have pointed in this introductory paper to the possibility of tensions and conflict in the next decade. The papers in the special issue all in different ways point towards this dilemma. The topics addressed in each could be the basis for the emergence of a mobilities sub-field (around for instance theories of governance, automobility, aeromobility, method, inequality etc), with the associated power struggles and search for goods. Or, the topics could be the basis in the next decade for the further development of open discussions about what mobilities research can achieve without settling into expected or entrenched 
sub-fields. We prefer a vision built on the latter scenario; while convergence and coalescence bring advantages for conceptual development, excitement and contribution, we feel this must not be pursued without a grounding in the interdisciplinary inspiration that has enlivened mobilities research in the last decade, and which encourages an openness to unexpected conversations, sites of study, and overlaps between individual and collective concerns and priorities.

Hence, for us, the primary concern in the next decade should not be what mobilities research is, what it should be, or what distinguishes it in internally as a series of sub-fields or in relation to other fields. Rather it should relate to the continuation of dialogues about mobilities - broadly writ - in an exciting, open, and creative shared culture that both draws from but also contributes to the wider social sciences. Evolutions within the field will be an important part of this creativity, and are likely to lead to a mix of both closing down (some theoretical coalescence to incrementally develop important agendas) and the maintaining of porosity (a continued commitment to taking mobility seriously as an object of study and drawing on the most appropriate tools to do this as new issues arise). It is incumbent on mobilities researchers, through their practices, to curate such a field.

The importance of engaging with politically important questions such as climate change and inequalities highlight why a mix of selective closing down alongside generous openness seems important: we need both to 'stand on the shoulders of giants' in our theoretical efforts to deal with such issues (for example through theoretically focussed sub-fields), but also respond to the ever evolving nature of the challenges before us (requiring the embracing of new approaches). This special issue is, therefore, our salute to the benefits of the approach of the past decade, to all of the questions not yet asked, and to the rich conversations that they might spark in an evolving (and inevitably changing) field in the future.

\section{Acknowledgements}

The editors of the special issue would like to thank the Reviewers for their generosity in commenting on all of the submissions and helping enhance each and every paper, including this introduction. As always, Pennie Drinkall provided outstanding assistance in the CeMoRE and Mobilities office. We also thank Jen Southern (Lancaster University) for her input and support in the early stages of developing this special issue.

\section{Bibliography}

Abbott, A. (2001) Chaos of disciplines (Chicago: University of Chicago Press).

Adey, P. (2008) Airports, mobility and the calculative architecture of affective control, Geoforum 39, pp. 438-451.

Adey, P., et al. (2014a) Introduction, in P. Adey, et al. (Eds.) The Routledge handbook of mobilities, pp. 1-20 (London: Routledge).

--- (Eds.) (2014b) The Routledge handbook of mobilities (London: Routledge).

Aldred, R. and Jungnickel, K. (2013) Matter in or out of place? Bicycle parking strategies and their effects on people, practices and places, Social \& Cultural Geography 14 (6), pp. 604-624.

Anim-Addo, A., Hasty, W., and Peters, K. (2014) The Mobilities of Ships and Shipped Mobilities, Mobilities 9 (3), pp. 337-349. 
Bajc, V., Coleman, S., and Eade, J. (2007) Introduction: mobility and centring in pilgrimage, Mobilities 2 (3), pp. 321-329.

Barker, J., et al. (2009) The road less travelled-new directions in children's and young people's mobility, Mobilities 4 (1), pp. 1-10.

Basu, P. and Coleman, S. (2008) Introduction: migrant worlds, material cultures, Mobilities 3 (3), pp. 313-330.

Benson, M. (2011) The movement beyond (lifestyle) migration: mobile practices and the constitution of a better way of life, Mobilities 6 (2), pp. 221-235.

Bissell, D. (2009) Conceptualising differently-mobile passengers: geographies of everyday encumbrance in the railway station, Social \& Cultural Geography 10 (2), pp. 173-195.

--- (2010) Passenger mobilities: affective atmospheres and the sociality of public transport, Environment and Planning D: Society and Space 28, pp. 270-289.

Blok, A. (2010) Mapping the super-whale: towards a mobile ethnography of situated globalities, Mobilities 5 (4), pp. 507-528.

Böhm, S., et al. (2006) Introduction: impossibilities of automobility, Sociological Review 54 (s1), pp. 1-16.

Bourdieu, P. (1984) Distinction: a social critique of the judgement of taste, trans. R. Nice (London: Routledge).

Budd, L.C.S. (2011) On being aeromobile: airline passengers and the affective experiences of flight, Journal of Transport Geography 19, pp. 1010-1016.

Burrell, K. (2008) Materialising the border: spaces of mobility and material culture in migration from post-socialist Poland, Mobilities 3 (3), pp. 353-373.

Büscher, M. and Urry, J. (2009) Mobile methods and the empirical, European Journal of Social Theory 12 (1), pp. 99-116.

Büscher, M., Urry, J., and Witchger, K. (Eds.) (2011) Mobile methods (London: Routledge).

Conley, J. and McLaren, A.T. (Eds.) (2009) Car troubles: critical studies of automobility (Farnham: Ashgate).

Conradson, D. and Latham, A. (2007) The affective possibilities of London: Antipodean transnationals and the overseas experience, Mobilities 2 (2), pp. 231-254.

Conradson, D. and McKay, D. (2007) Translocal subjectivities: mobility, connection, emotion, Mobilities 2 (2), pp. 167-174.

Cresswell, T. (2006) On the move: mobility in the modern Western world (London: Routledge).

--- (2010) Towards a politics of mobility, Environment and Planning D: Society and Space 28 (1), pp. 17-31.

--- (2011) Mobilities I: catching up, Progress in Human Geography 35 (4), pp. 550-558.

--- (2012) Mobilities II: still, Progress in Human Geography 36 (5), pp. 645-653.

--- (2014) Mobilities III: Moving on, Progress in Human Geography, pp.

Cresswell, T. and Merriman, P. (Eds.) (2011) Geographies of mobilities: practices, spaces, subjects (Farnham: Ashgate).

Cwerner, S., Kesselring, S., and Urry, J. (Eds.) (2009) Aeromobilities (New York: Routledge).

DiMaggio, P.J. and Powell, W.W. (1983) The iron cage revisited: Institutional isomorphism and collective rationality in organizational fields, American sociological review 48 (2), pp. 147160.

Farías, I. (2010) Sightseeing buses: cruising, timing and the montage of attractions, Mobilities 5 (3), pp. 387-407.

Featherstone, M., Thrift, N., and Urry, J. (Eds.) (2005) Automobilities (London: Sage).

Fincham, B., McGuinness, M., and Murray, L. (Eds.) (2010) Mobile methodologies (Basingstoke: Palgrave Macmillan).

Fligstein, N. and McAdam, D. (2012) A theory of fields (Oxford: Oxford University Press).

Fortier, A.M. and Lewis, G. (2006) Editorial: Migrant Horizons, pp. 
Gill, N., Caletrio, J., and Mason, V. (2011) Introduction: mobilities and forced migration, Mobilities 6 (3), pp. 301-316.

Hannam, K., Sheller, M., and Urry, J. (2006) Mobilities, immobilities and moorings, Mobilities 1 (1), pp. 1-22.

Hargadon, A.B. and Douglas, Y. (2001) When innovations meet institutions: Edison and the design of the electric light, Administrative Science Quarterly 46 (3), pp. 476-501.

Hein, J.R., Evans, J., and Jones, P. (2008) Mobile methodologies: theory, technology and practice, Geography Compass 2 (5), pp. 1266-1285.

Hui, A. (2012) Things in motion, things in practices: how mobile practice networks facilitate the travel and use of leisure objects, Journal of Consumer Culture 12 (2), pp. 195-215.

--- (2013) Moving with practices: the discontinuous, rhythmic and material mobilities of leisure, Social \& Cultural Geography 14 (8), pp. 888-908.

Jensen, O.B. (2006) 'Facework', flow and the city: Simmel, Goffman, and mobility in the contemporary city, Mobilities 1 (2), pp. 143-165.

--- (2009) Flows of meaning, cultures of movements: urban mobility as meaningful everyday life practice, Mobilities 4 (1), pp. 139-158.

--- (2010) Negotiation in motion: unpacking a geography of mobility, Space and Culture 13 (4), pp. 389-402.

Jensen, O.B., Sheller, M., and Wind, S. (2014), 'Together and apart: affective ambiences and negotiation in families' everyday life and mobility', Mobilities, $<$ http://dx.doi.org/10.1080/17450101.2013.868158\%3E, accessed 18 March 2015.

Kidder, J.L. (2009) Mobility as strategy, mobility as tactic: post-industrialism and bike messengers, in P. Vannini (Ed.) The cultures of alternative mobilities: routes less travelled, pp. 177-191 (Surrey, UK: Ashgate).

Knight, K. (Ed.) (1998) The MacIntyre reader (Notre Dame, Indiana: University of Notre Dame Press). Larsen, J. (2008a) De-exoticizing tourist travel: everyday life and sociality on the move, Leisure Studies 27 (1), pp. 21-34.

--- (2008b) Practices and flows of digital photography: an ethnographic framework, Mobilities 3 (1), pp. 141-160.

Larsen, J., Urry, J., and Axhausen, K. (2006) Mobilities, networks, geographies (Aldershot, UK: Ashgate).

Lassen, C. (2006) Aeromobility and work, Environment and Planning A 38, pp. 301-312.

Licoppe, C. (2009) Recognizing mutual 'proximity' at a distance: weaving together mobility, sociality and technology, Journal of Pragmatics 41, pp. 1924-1937.

Maclntyre, A. (1985) After virtue: a study in moral theory (Second edn.; London: Duckworth).

Manderscheid, K., Schwanen, T., and Tyfield, D. (2014) Introduction to Special Issue on 'Mobilities and Foucault', Mobilities 9 (4), pp. 479-492.

McHugh, K.E. (2009) Movement, memory, landscape: an excursion in non-representational thought, GeoJournal 74, pp. 209-218.

Merriman, P. (2015) Mobilities I Departures, Progress in Human Geography 39 (1), pp. 87-95.

Navis, C. and Glynn, M.A. (2010) How new market categories emerge: temporal dynamics of legitimacy, identity, and entrepreneurship in satellite radio, 1990-2005, Administrative Science Quarterly 55 (3), pp. 439-471.

Nowicka, M. (2007) Mobile locations: constructions of home in a group of mobile transnational professionals, Global Networks 7 (1), pp. 69-86.

Ren, C. (2011) Non-human agency, radical ontology and tourism realities, Annals of Tourism Research 38 (3), pp. 858-881.

Richardson, T. (2013) Borders and mobilities: introduction to the special issue, Mobilities 8 (1), pp. 16. 
Scott, W.R. (1994) Conceptualizing organizational fields: Linking organizations and societal systems, in J. Derlien, U. Gerhardt, and F. Scharpf (Eds.) Systems rationality and parcial interests, pp. 203-221 (Baden: Nomos).

Sheller, M. (2014) Sociology after the mobilities turn, in P. Adey, et al. (Eds.) The Routledge handbook of mobilities, pp. 45-54 (London: Routledge).

Sheller, M. and Urry, J. (2006) The new mobilities paradigm, Environment and Planning A 38, pp. 207-226.

Spinney, J. (2011) A chance to catch a breath: using mobile video ethnography in cycling research, Mobilities 6 (2), pp. 161-182.

Urry, J. (2000) Sociology beyond societies: mobilities for the twenty-first century (London: Routledge).

--- (2007) Mobilities (Cambridge: Polity Press).

Vannini, P. (2011) The techne of making a ferry: a non-representational approach to passengers' gathering taskscapes, Journal of Transport Geography 19, pp. 1031-1036.

Warde, A. (2004), 'Practice and field: revising Bourdieusian concepts', CRIC Discussion Paper, Centre for Research on Innovation \& Competition <http://www.cric.ac.uk/cric/Pdfs/DP65.pdf\%3E, accessed 18 March 2015.

Yeoh, B.S.A. and Huang, S. (2010) Transnational domestic workers and the negotiation of mobility and work practices in Singapore's home-spaces, Mobilities 5 (2), pp. 219-236. 